\title{
Groundwater evapotranspiration under psammophilous vegetation covers in the Mu Us Sandy Land, northern China
}

\author{
CHENG Donghui $^{1 *}$, DUAN Jibo ${ }^{1}$, QIAN Kang ${ }^{1}$, QI Lijun ${ }^{1}$, Yang Hongbin ${ }^{1}$, \\ CHEN Xunhong ${ }^{2 \dagger}$ \\ ${ }^{1}$ School of Environmental Sciences and Engineering, Chang'an University, Xi'an 710054, China; \\ ${ }^{2}$ School of Nature Resources, University of Nebraska-Lincoln, NE68583-0996, USA
}

\begin{abstract}
Groundwater is a significant component of the hydrological cycle in arid and semi-arid areas. Its evapotranspiration is an important part of the water budget because many plants are groundwater-dependent. To restore the degraded ecosystems, the need is pressing to further our understanding of the groundwater evapotranspiration $\left(\mathrm{ET}_{\mathrm{g}}\right)$ in arid and semi-arid areas. This study employed the White method to estimate $\mathrm{ET}_{\mathrm{g}}$ at four sites in the Mu Us Sandy Land in northern China, and the four sites are covered by Salix psammophila (SP site), Artemisia ordosica (AO site), Poplar alba (PA site), and Carex enervis (CE site), respectively. The depth of groundwater table and the duration of drainage were taken into account in calculating the specific yield $\left(\mathrm{S}_{\mathrm{y}}\right)$ to improve the accuracy of the $\mathrm{ET}_{\mathrm{g}}$ estimats. Our results showed that from late May to early November 2013 the $\mathrm{ET}_{g}$ were 361.87 (SP site), 372.53 (AO site), 597.86 (PA site) and $700.76 \mathrm{~mm}$ (CE site), respectively. The estimated $\mathrm{ET}_{\mathrm{g}}$ rate was also species-dependent and the descending order of the $\mathrm{ET}_{\mathrm{g}}$ rate for the four vegetation was: C. enervis, P. alba, A. ordosica, and S. psammophila. In addition, the depth of groundwater table has an obvious effect on the $\mathrm{ET}_{\mathrm{g}}$ rate and the effect varied with the vegetation types. Furthermore, the evapotranspiration for the vegetation solely relying on the water supply from unsaturated layers above the groundwater table was much less than that for the vegetation heavily relying on the water supply from shallow aquifers.
\end{abstract}

Keywords: groundwater evapotranspiration; White method; specific yield; psammophilous vegetation; Mu Us Sandy Land

Citation: CHENG Donghui, DUAN Jibo, QIAN Kang, QI Lijun, YANG Hongbin, CHEN Xunhong. 2017. Groundwater evapotranspiration under psammophilous vegetation covers in the Mu Us Sandy Land, northern China. Journal of Arid Land, 9(1): 98-108. doi: 10.1007/s40333-016-0095-7

\section{Introduction}

Effective and sustainable water resource management requires information on all components of the hydrological cycle and groundwater is a significant component of the cycle. Within groundwater systems, groundwater evapotranspiration $\left(\mathrm{ET}_{\mathrm{g}}\right)$ is an important part of the groundwater budget, especially in arid and semi-arid areas where many plants are groundwater-dependent. To restore the degraded ecosystems or/and to maintain the existing healthy ecosystems, the need is thus pressing to further our understanding of the $\mathrm{ET}_{\mathrm{g}}$ in arid and semi-arid areas (Feng et al., 2012).

The traditional methods for measuring or estimating evapotranspiration, including the Penman

${ }^{*}$ Corresponding author: CHENG Donghui (E-mail: chdhbsh@chd.edu.cn)

†Deceased

Received 2015-09-15; revised 2016-06-08; accepted 2016-06-22

(C) Xinjiang Institute of Ecology and Geography, Chinese Academy of Sciences, Science Press and Springer-Verlag Berlin Heidelberg 2017 
method, energy balance method, remote sensing method, eddy covariance method, lysimeter method, and sap flow method, etc., are not able to directly obtain $\mathrm{ET}_{\mathrm{g}}$. To estimate $\mathrm{ET}_{\mathrm{g}}$, White (1932) proposed a groundwater-level hydrograph method (hereinafter referred to as the White method) and the method was based on the observation of water table diurnal fluctuations. This method comes from the idea that if plants use groundwater as main source of water supply, the water table should display diurnal fluctuations in response to the daily water consumed by plants. This method is straightforward and relatively simple to calculate $\mathrm{ET}_{\mathrm{g}}$ rate with a relatively low cost. In the past several decades, the White method has been repeatedly approved to be acceptable by many researchers (Troxell, 1936; Gatewood, et al., 1950; Tromble, 1977; Gerla, 1992; Rosenberry and Winter, 1997).

In the White method, the specific yield $\left(\mathrm{S}_{\mathrm{y}}\right)$, defined as the volume of water that is withdrawn from or recharged to an aquifer (Freeze and Cherry, 1979), is a key parameter for estimating ET $_{\mathrm{g}}$. Although $S_{y}$ value was generally assumed to be a constant in most of hydrological studies, the $S_{y}$ value actually varies from site to site, depending not only on the depth of water table but also on the duration of drainage. Especially in shallow groundwater systems, the dependency of $\mathrm{S}_{\mathrm{y}}$ on the depth of water table is significant and thus should not be neglected. To take into account the variability of $S_{y}$ values, researchers have attempted to establish the relationship of the $S_{y}$ value with the depth of water table or/and the duration of drainage (Duke, 1972; Cheng et al., 2014). For example, Nachabe (2002) proposed a closed-form expression to capture the relationship of the $S_{y}$ value with the depth of water table and the duration of drainage. This relationship was further verified by a number of researches (e.g., Loheide et al., 2005; Cheng et al., 2013).

It should be particularly noted that the White method was rarely applied to other environments although it has been proven to be effective in riparian environments due to the apparent diurnal water table fluctuation. We, the authors of this paper, speculate that desert may be another suitable environment to use the White method for estimating the $\mathrm{ET}_{\mathrm{g}}$ because the plants with deep root systems (e.g., trees and shrubs) or the plants relying on shallow groundwater (e.g., grasses) in desert environments are intensively consuming the groundwater. In this study, the $\mathrm{ET}_{\mathrm{g}}$ rates under four different vegetation types in the Mu Us Sandy Land were estimated using the White method, and three equations of calculating the $S_{y}$ values for the eolian sand aquifer were compared and evaluated. Temporal variation patterns of the $\mathrm{ET}_{\mathrm{g}}$ rates for the four vegetation types during a 6-month monitoring period were presented.

\section{Materials and methods}

\subsection{Site description and data sets}

The Mu Us Sandy Land covers an area of about $40 \times 10^{3} \mathrm{~km}^{2}$ and its major portion is situated within the Inner Mongolia Autonomous Region, northern China. The annual mean temperature ranges from $6.0^{\circ} \mathrm{C}$ to $8.5^{\circ} \mathrm{C}$ and the mean annual precipitation from 250 to $440 \mathrm{~mm}$ from the northwest to the southeast. Precipitation is mainly concentrated in summer months from July to September (Cheng et al., 2011; Yan et al., 2013). In recent years, with rapid development of petrochemical industries in the area, the demand for water greatly increased and the groundwater is perceived to be a reliable water source for the industries. This surely poses an enormous threat to the ecosystems that heavily rely on the groundwater and the threat thus warns us pay particular attentions to the ecological need of the groundwater. However, we have little knowledge about the relationship between vegetation and groundwater (Cheng et al., 2011).

The study site is located in the center of the Mu Us Sandy Land (Fig. 1). The site is featured by stable sand dunes and dune slacks. Four vegetation types can be readily differentiated along a transect from the leeward side (i.e., site 1 in Fig. 2), through the upper windward slope (site 2) and the lower windward slope (site 3), to the far front of the dunes (site 4). That is, Poplar alba distributes at the leeward side of sandunes; Artemisia ordosica at the upper windward slope and Salix psammophila at the lower windward slope; and Carex enervis at the far front of sandunes or dune slacks (hereinafter the four sites mentioned above will be referred as PA, SP, AO, CE sites, respectively). Generally, the heights of a single S. psammophila, A. Ordosica, P. alba and C. 
enervis are around $2.2,1.5,8.5$ and $0.2 \mathrm{~m}$, respectively; and the crown diameters are around 1.8, $1.5,5.0$ and $0.1 \mathrm{~m}$, respectively. The percentages of plant coverage are around $75 \%, 40 \%, 50 \%$ and $45 \%$ of the land surface at the CE, AO, PA, and SP sites, respectively. Groundwater exists in the eolian sand aquifer with a greater than $50-\mathrm{m}$ saturation thickness and the aquifer has good transmissivity and storativity. There are only two local shepherd households residing within the $2-\mathrm{km}$ radius of the study site. Thus, groundwater used by other processes, such as groundwater extraction and irrigation, can be neglected.

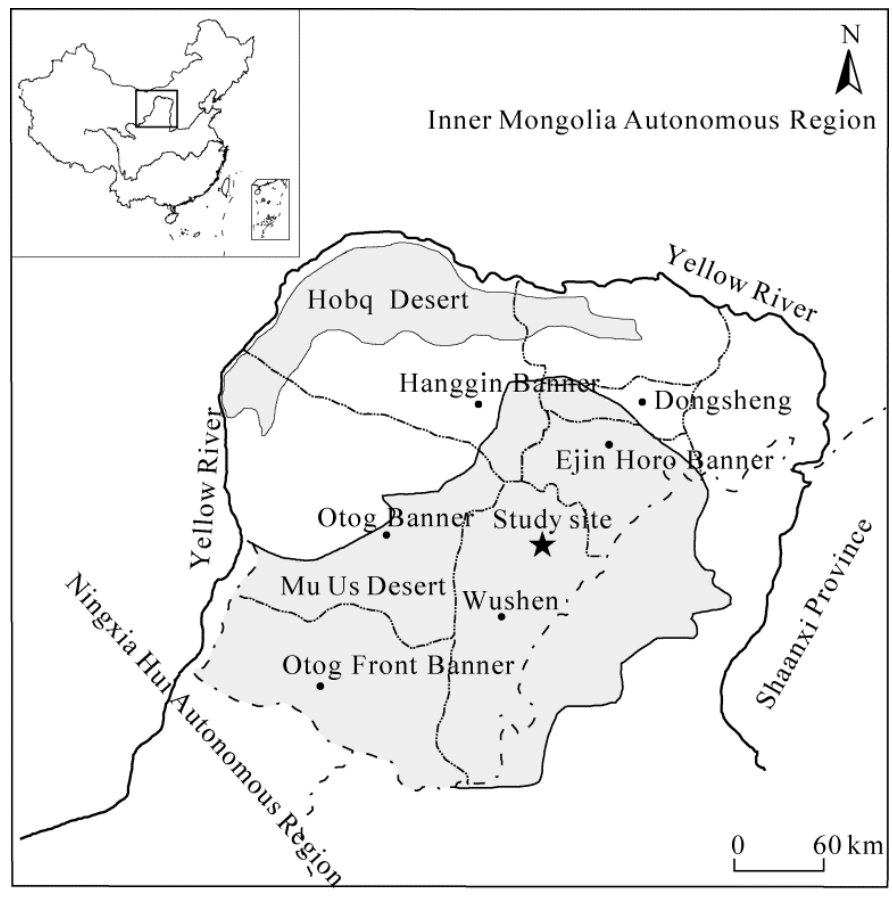

Fig. 1 Location of the study site in the Mu Us Sandy Land
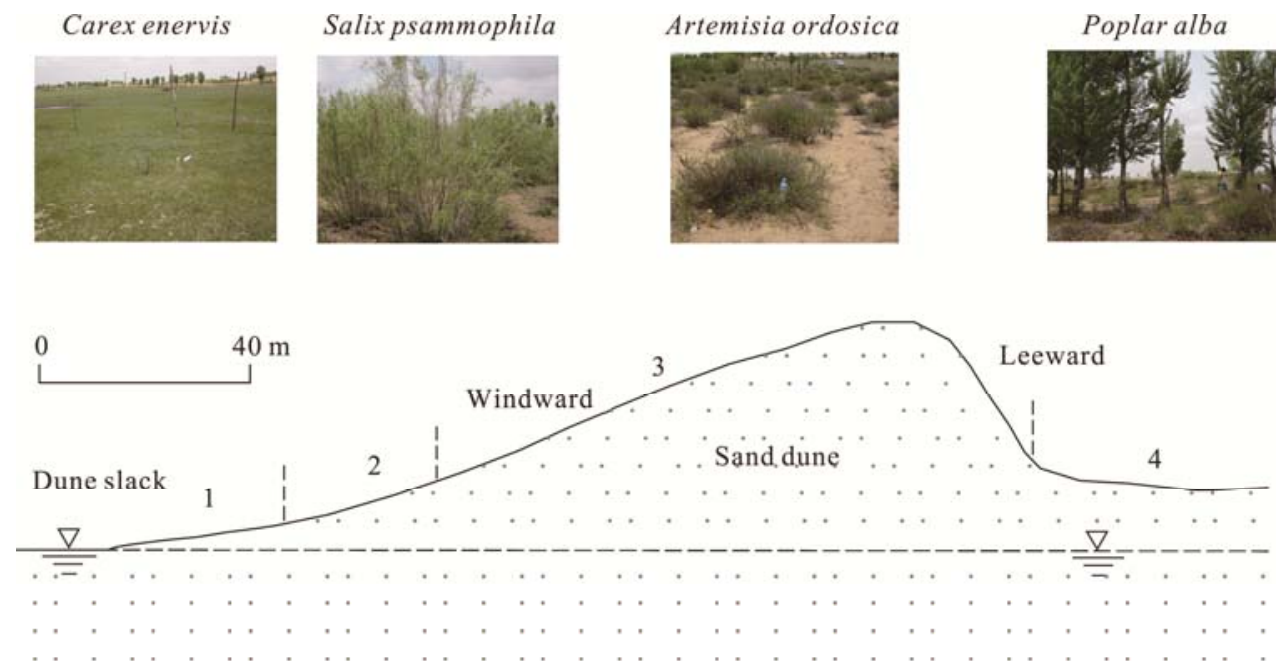

Fig. 2 Schematic map showing four vegetation types at the study sites. The numbers of 1, 2, 3 and 4 denote the four monitoring sites covered by Carex enervis, Salix psammophila, Artemisia ordosica and Poplar alba, respectively.

Monitoring wells were constructed in each one of the four vegetation zones in May 2013 and a 4.2-cm diameter PVC screen was installed in each well. The water table and the barometric 
pressure were automatically recorded at 5-min intervals during the plant growing seasons from 25 May to 11 November 2013. A tipping bucket typological rainfall gauge with an accuracy of 0.1 $\mathrm{mm}$ was installed to record the on-site precipitation.

\subsection{The White method}

Estimation of $\mathrm{ET}_{\mathrm{g}}$ rates by the White method was based on the daily groundwater table fluctuations observed at the monitoring wells. The rates were calculated according to Equation 1 (White, 1932).

$$
E T_{g}=S_{y}(24 r \pm s) \text {. }
$$

Where $S_{y}$ (dimensionless) is the specific yield of the aquifer sediments; $r$ is the rate of the groundwater table change between 00:00 and 04:00 (24-h clock); $s$ is the net change of the groundwater table during a $24-\mathrm{h}$ period. The value of $r$ (dimensionless) was quantified daily at each site as the slope of the water-table graph between 00:00 and 04:00 (Fig. 3). During this period (i.e., between 00:00 and 04:00), the $\mathrm{ET}_{\mathrm{g}}$ is rather limited due to a rather weak photosynthesis and therefore $r$ represents the groundwater influx rate. This method assumes that the daily groundwater influx rate is constant and that the water-table change in response to $\mathrm{ET}_{\mathrm{g}}$ can be quantified by taking the difference between the actual groundwater table depth at the end of the day and the groundwater table depth expected to be if the groundwater table at the site was controlled only by the groundwater flow.

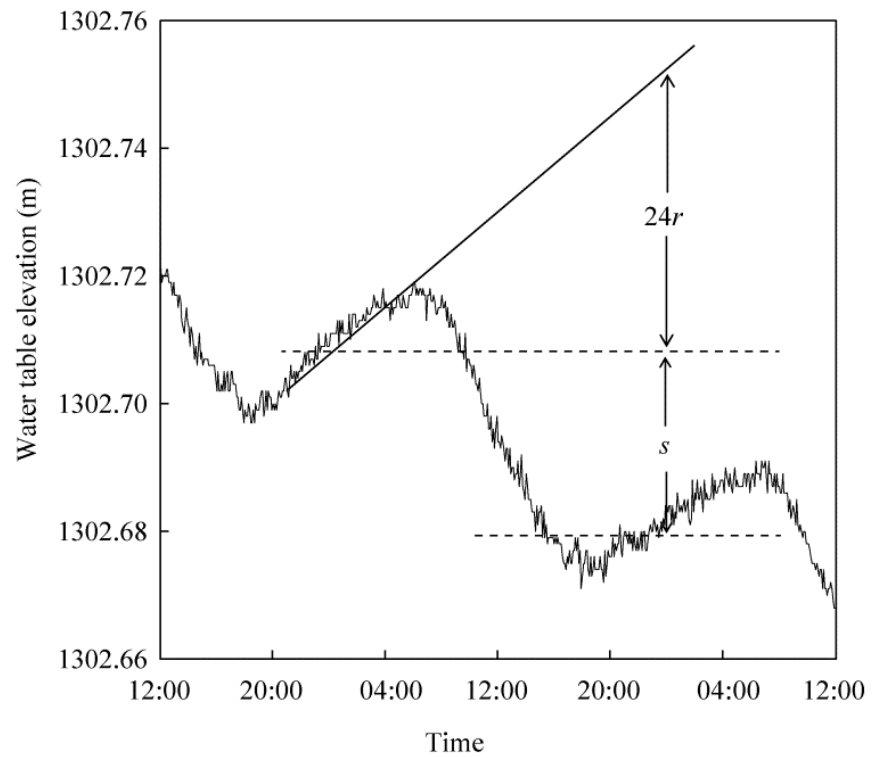

Fig. 3 Daily hydrograph for estimating groundwater evapotranspiration $\left(\mathrm{ET}_{\mathrm{g}}\right)$

\subsection{Specific yield $\left(S_{y}\right)$}

Based on the soil-water retention model (Brooks and Corey, 1964), Duke (1972) proposed an expression, i.e., Equation 2, to capture the $\mathrm{S}_{\mathrm{y}}$ that varies with the depth of groundwater table.

$$
S_{y}=\left(\theta_{s}-\theta_{r}\right)\left[1-\left(\frac{h_{a}}{d}\right)\right]^{\lambda} .
$$

Where $\lambda$ (dimensionless) and $h_{a}$ are the pore size distribution index and soil air-entry pressure head of the Brooks and Corey water retention model, respectively; $d$ is the depth of groundwater table, and $\theta_{s}$ and $\theta_{r}$ are the saturated water content and the residual volumetric water content, respectively. Cheng et al. (2014) proposed an analytical expression to describe the relationship between the $\mathrm{S}_{\mathrm{y}}$ and the depth of groundwater tables using the van Genuchten soil-water retention model (Eq. 3). 


$$
S_{y}=\theta_{s}-\left[\theta_{r}+\frac{\theta_{s}-\theta_{r}}{\left[1+(\alpha d)^{n}\right]^{m}}\right] .
$$

Where $\alpha$ is a parameter related to the inverse of the air-entry value; $m$ and $n$ are dimensionless parameters; The $n$ value is generally restricted to values greater than one so that the slope of the soil water retention curve is zero as the water content approaches saturation; $m$ and $n$ are related through the equation $m=1-1 / n$.

Nachabe (2002) proposed a closed-form expression for determining $\mathrm{S}_{\mathrm{y}}$ given the depth of groundwater table and the duration of drainage after a step change in the depth of the groundwater table. This method is based on the Brooks and Corey water retention model. This expression can provide insight into the dependency of $S_{y}$ on both the duration of drainage and the depth of groundwater table. The expression is as Equation 4 when an initial groundwater table $d_{1}$ drops to $d_{2}$,

$$
\begin{aligned}
S_{y}(t)= & \frac{\theta_{s}-\theta_{r}}{\Delta}\left[d_{1}\left(\Theta_{\text {suri }}-\Theta_{\text {sur }}\right)-\frac{\lambda h_{a}}{\lambda-1}\left(\Theta_{\text {suri }}^{(\lambda-1) / \lambda}-\Theta_{\text {sur }}^{(\lambda-1) / \lambda}\right)\right] \\
& +\frac{K_{s}}{\Delta}\left(\Theta_{b}^{i}-\Theta_{\text {sur }}^{i}\right) t+\left(\varphi-\theta_{r}\right)\left(1-\Theta_{b}\right) .
\end{aligned}
$$

Where $K_{s}$ is saturated hydraulic conductivity; $t$ is time; $\varphi$ is matric potential; the dimensionless exponent $i$ can be set equal to $(2+3 \lambda) / \lambda$, the water table fluctuation $\Delta=d_{2}-d_{1}, \Theta_{b}, \Theta_{\text {sur }}$ and $\Theta_{\text {suri }}$ are the dimensionless normalized water content, surface soil water content and initial surface soil water content, respectively.

$$
\Theta_{b}=\frac{\theta_{b}-\theta_{r}}{\varphi-\theta_{r}}=\left(\frac{\Delta\left(\varphi-\theta_{r}\right)}{n K_{s}}\right)^{1 / i-1} t^{1 / i-1}, \Theta_{\text {suri }}=\left(h_{\mathrm{a}} / d_{1}\right)^{\lambda},
$$

and $\Theta_{\text {sur }}$ is determined from the following equation:

$$
d_{2}=\Delta+h_{a} \Theta_{\text {sur }}^{-1 / \lambda}-\frac{i K_{s}}{\varphi-\theta_{r}} \Theta_{\text {sur }}^{i-1} t .
$$

The $\mathrm{S}_{\mathrm{y}}$ values calculated by the above three equations (Eqs. 2-4) were compared and discussed in the following section.

\section{Results and discussion}

\subsection{Diurnal fluctuation of groundwater table}

During growing seasons, the hydrographs at the four wells all showed typical patterns of diurnal fluctuations, being rather consistent with observations by other researches. The groundwater table tends to decline after sunrise due to strong photosynthesis, and then to rise after sunset because of the lateral flow of groundwater recharge and the weakened photosynthesis (White, 1932; Loheide et al., 2005; Butler et al., 2007). Generally speaking, groundwater table declined to a trough at around 18:00 to 20:00 and rose to a crest at around 07:00 to 09:00. In addition, the diurnal fluctuations gradually disappeared when vegetation began to enter into defoliation and dormancy. In June and July, the daily amplitude of groundwater table fluctuation had a maximum value of around 60, 30, 15 and $40 \mathrm{~mm}$ at the CE, SP, AO, and PA sites, respectively; and after July it reduced gradually until the regular waving fluctuations disappeared (Fig. 4). It should be particularly noted that the unexpected smooth hydrographs in June at the four wells should be taken as "invalid" because the observed excessive decline of the groundwater table exposed the pressure transducers above the groundwater table, resulting in "incorrect" measurements.

The White method is not applicable during rainfall events because the assumption of the constant groundwater influx rate throughout the day is not satisfied. Therefore, it is necessary to identify the groundwater table fluctuations resulted from the rainfall events. A total rainfall amounts of $379.7 \mathrm{~mm}$ was recorded during the monitoring period and the most of the amounts 
occurred between June and September (Fig. 4). The bottom panel of Figure 4 (i.e., Fig. 4e) shows the rainfall events during the monitoring period.

\subsection{Specific yield $\left(\mathrm{S}_{\mathrm{y}}\right)$}

The $S_{y}$ values were estimated using Equations 2, 3 and 4, respectively. The groundwater tables in Equations 2 and 3 were obtained from the daily average value of diurnal variation. The initial groundwater table $\left(d_{1}\right)$ in Equation 3 was obtained from the groundwater table at 00:00 each day and the $\Delta$ in Equation 4 was the declined values of groundwater table throughout the day. The relevant parameter values in the three equations were listed in Table 1 . The calculated $\mathrm{S}_{\mathrm{y}}$ values at the four sites were shown in Figure 5, respectively.

The $\mathrm{S}_{\mathrm{y}}$ values obtained from Equation 2 were greater than those from Equation 3 when the groundwater table was less than $\sim 2 \mathrm{~m}$ while the $S_{\mathrm{y}}$ values from Equation 2 were approximately equal to those from Equation 3 when the groundwater table was greater than $\sim 2 \mathrm{~m}$ (Fig. 5). The two water retention curves, one from the Brooks and Corey model and the other from the van
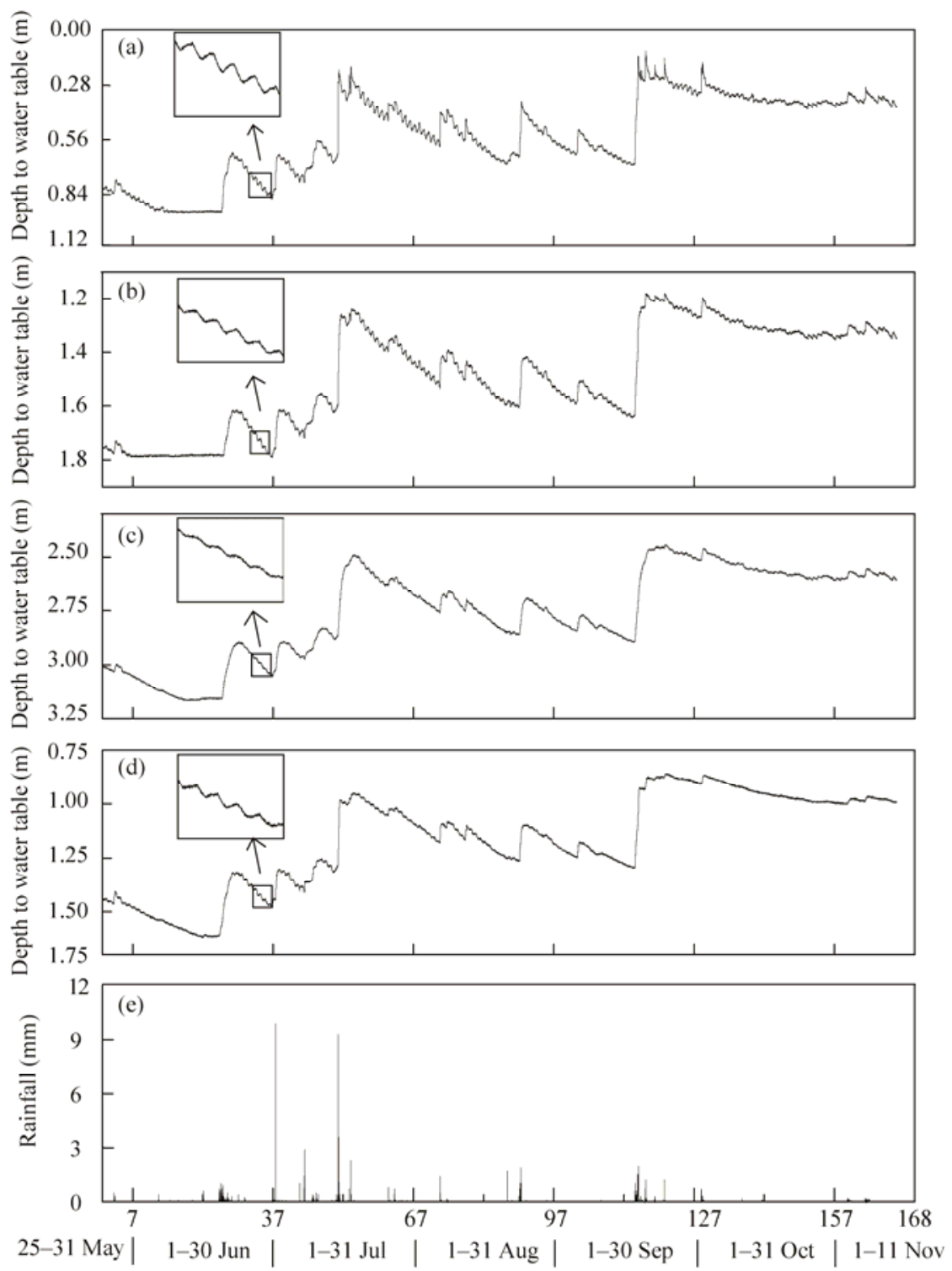

Fig. 4 Variations of the depths of groundwater tables at Carex enervis (CE site, a), Poplar alba (PA site, b), Artemisia ordosica (AO site, c) and Salix psammophila (SP site, d) 
Table 1 Adopted parameters of the Brooks-Corey model for the eolian sand in the study site

\begin{tabular}{ccccc}
\hline$\theta_{s}\left(\mathrm{~cm}^{3} / \mathrm{cm}^{3}\right)$ & $\theta_{r}\left(\mathrm{~cm}^{3} / \mathrm{cm}^{3}\right)$ & $h_{a}(\mathrm{~cm})$ & $\lambda$ & $K_{s}(\mathrm{~m} / \mathrm{d})$ \\
\hline 0.365 & 0.078 & 21 & 2.6 & 2.47 \\
\hline
\end{tabular}

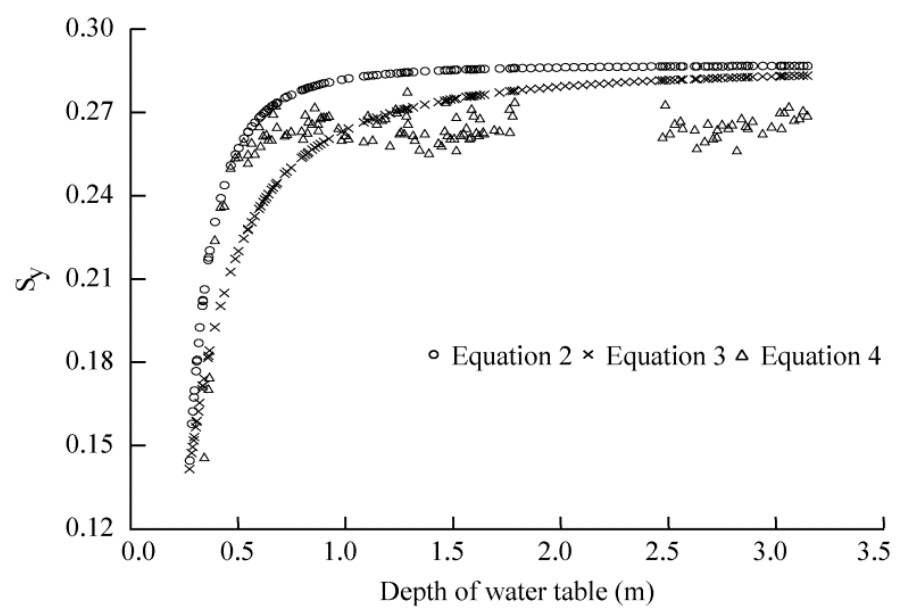

Fig. 5 Calculated Specific yield $\left(S_{y}\right)$ values using Equations 2, 3 and 4, respectively

Genuchten model, had different shapes at smaller depth of the groundwater table, and this difference was resulted from the inconformity of the $S_{y}$ from Equations 2 and 3. The maximum difference of $\mathrm{S}_{\mathrm{y}}$ values between these two curves occurred at the groundwater table of $0.5 \mathrm{~m}$. Equation 4 was also derived based on the Brooks and Corey model, and the $S_{y}$ values from this equation (Eq. 4) were also greater than those from Equation 3 when the groundwater table was less than $\sim 0.9 \mathrm{~m}$. In addition, when both the duration of drainage and the depth of groundwater table were considered in Equation 4, the $S_{\mathrm{y}}$ values from this equation were less than those from Equation 2 in which $S_{y}$ was only dependent on the depth of groundwater table.

The water retention curve for the eolian sand has an S-shape, i.e., it fits the van Genuchten model, and the $S_{y}$ is the function of both the depth of groundwater table and the duration of drainage. Theoretically speaking, an $\mathrm{S}_{\mathrm{y}}$ expression, which was derived from the van Genuchten model and took into account both the depth of groundwater table and the duration of drainage, is more accurate for estimating the $\mathrm{ET}_{\mathrm{g}}$ in the eolian sand aquifer using the White method. From this point of view, the three $S_{y}$ expressions listed in Equations 2-4 did not adequately meet the expectation for accurately estimating the $\mathrm{ET}_{\mathrm{g}}$ rates. However, Figure 5 illustrated the transient $\mathrm{S}_{\mathrm{y}}$ expression (Eq. 4), which could estimate the value than the ultimate $\mathrm{S}_{\mathrm{y}}$ (Eqs. 2 and 3) more accurately when the groundwater table was greater than $\sim 0.9 \mathrm{~m}$, whereas the ultimate $\mathrm{S}_{\mathrm{y}}$ expressions may overestimate the $\mathrm{S}_{\mathrm{y}}$ values. For example, at the groundwater table of $2.5 \mathrm{~m}$, the $S_{y}$ value from Equation 4 was around 0.26, while the $S_{y}$ value from Equations 2 and 3 was $\sim 0.29$. Equations 2 and 3 may overestimate the $S_{y}$ value by as much as $11.5 \%$ at this groundwater table. Therefore, when the groundwater table was greater than $\sim 0.9 \mathrm{~m}$, the effect of the drainage time on the $S_{y}$ value was greater than that of the model-characterized water retention curve (e.g., the van Genuchten model or the Brooks and Corey model). However, when the groundwater table was less than $0.9 \mathrm{~m}$, the opposite is the case.

In this study, Equation 4 was applied for estimating the $S_{y}$ value when the groundwater table was greater than $0.9 \mathrm{~m}$ and Equation 3 was applied when the groundwater table was less than 0.9 $\mathrm{m}$.

\section{3 $\quad \mathrm{ET}_{\mathrm{g}}$ rates under four vegetation types}

$\mathrm{The}_{\mathrm{ET}}$ rates were estimated using the White method at the four sites that were covered with four different types of vegetation. The daily $\mathrm{ET}_{\mathrm{g}}$ rates were shown in Figure 6 and the average daily $\mathrm{ET}_{\mathrm{g}}$ rates of each month were shown in Figure 7. The $\mathrm{ET}_{\mathrm{g}}$ rates were largely controlled by the 

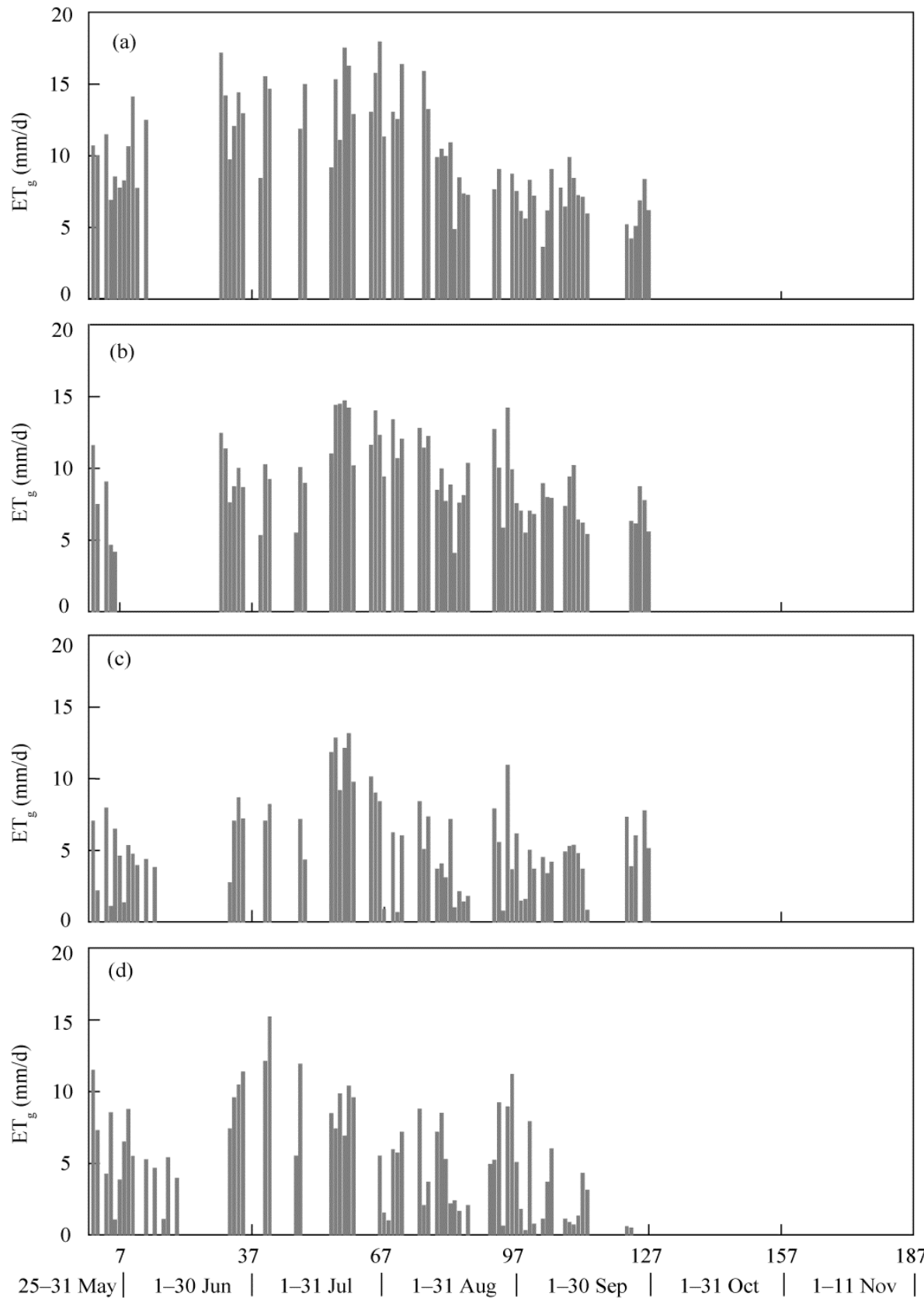

Fig. 6 Estimated daily $\mathrm{ET}_{\mathrm{g}}$ rates at CE site (a), PA site (b), AO site (c) and SP site (d), respectively

meteorological variables such as net solar radiation and temperature (Butler et al., 2007). Consequently, the $\mathrm{ET}_{\mathrm{g}}$ rates in July and August were higher than those in other months. However, the maximum monthly $\mathrm{ET}_{\mathrm{g}}$ of the four sites did not occur simultaneously. Specifically, the maximum appeared in July at $\mathrm{CE}$ and AO sites and the maximum occurred in August at PA and SP sites, suggesting that $C$. enervis and $A$. ordosica reached their maximal growth earlier than $P$. alba and $S$. psammophila. In addition, because $P$. alba and $S$. psammophila are deciduous species, the $\mathrm{ET}_{\mathrm{g}}$ at PA $(P . a l b a)$ and SP (S. psammophila) sites decreased sharply within a short period when leaves fell in late September. In contrast, the $\mathrm{ET}_{\mathrm{g}}$ for the non-deciduous $C$. enervis and $A$. ordosica gradually became weak at the beginning of October when they entered into the winter dormancy. 
The total values of $\mathrm{ET}_{\mathrm{g}}$ at SP, AO, PA, and CE sites during May-September (2013) were $361.87,372.53,597.86$ and $700.76 \mathrm{~mm}$, respectively. The $\mathrm{ET}_{\mathrm{g}}$ values at $\mathrm{SP}$ and AO sites were approximately equal to the rainfall amount of $379.7 \mathrm{~mm}$ for the observation period while the $\mathrm{ET}_{\mathrm{g}}$ values at PA and CE sites were far greater than the rainfall amount. However, the groundwater table as a whole rose rather than declined from the late May to the late September, indicating that the study sites belong to a groundwater discharge zone and that the recharge rate both from infiltrating rainfall and from the net lateral inflow of groundwater were greater than the $\mathrm{ET}_{\mathrm{g}}$ rates.

The estimated $\mathrm{ET}_{\mathrm{g}}$ rate was also species-dependent. For example, $C$. enervis had the highest $\mathrm{ET}_{\mathrm{g}}$ rate among the four vegetation types and the descending order of the $\mathrm{ET}_{\mathrm{g}}$ rate for the four vegetation was: $C$. enervis, $P$. alba, A. ordosica, and $S$. psammophila. In addition, the depth of groundwater table has an obvious effect on the $\mathrm{ET}_{\mathrm{g}}$ rate and the effect varied with the vegetation types. The results also obtained in the Mu Us Sandy Land by Cheng et al. (2013) showed that the average monthly $\mathrm{ET}_{\mathrm{g}}$ rates at SP site (S. psammophila) in July, August and September with a depth of groundwater table of $\sim 2.35 \mathrm{~m}$ were $0.70,0.45$ and $0.32 \mathrm{~mm} /$ day, respectively while the average monthly $\mathrm{ET}_{\mathrm{g}}$ rates at $\mathrm{AO}$ site (A. ordosica) with a depth of groundwater table of $5.35 \mathrm{~m}$ did not exhibit any monthly difference. However, the same study (Cheng et al., 2013) showed that the average monthly $\mathrm{ET}_{\mathrm{g}}$ rates at SP site in July, August and September with a depth of groundwater table of 1.0-1.5 m were up to $3.36,3.55$ and $1.06 \mathrm{~mm} /$ day, respectively, while the the average monthly $\mathrm{ET}_{\mathrm{g}}$ rates at $\mathrm{AO}$ site in those three months with a depth of groundwater table of $\sim 3.0 \mathrm{~m}$ were $3.99,3.03$ and $2.56 \mathrm{~mm} / \mathrm{d}$, respectively. These results demonstrate that the $\mathrm{ET}_{\mathrm{g}}$ varies with the depth of groundwater table. This finding is consistent with those by others. For example, Cooper et al. (2006) found that a 1.6-m drop in the depth of groundwater table has resulted in a $62 \%$ reduction in $\mathrm{ET}_{\mathrm{g}}$ in the San Luis Valley of southern Colorado, USA. Although the reported $62 \%$ reduction in the San Luis Valley may be an exaggerated expression due to large-scale groundwater pumping, it is still valid in confirming that the depth of groundwater table has significant effects on the $\mathrm{ET}_{\mathrm{g}}$.

\section{4 $\quad \mathbf{E T}_{\mathrm{g}}$ and soil water transpiration}

A number of researches have been conducted to obtain the evapotranspiration rates or the transpiration rates with respect to the aforementioned four vegetation types in the Mu Us Sandy Land using various methods and the used methods include steady porometer, Quick-weighing technique, photosynthetic measurements, and water balance method. It should be noted that most of the measurements were performed under the conditions where the groundwater table was deeper than the reach of vegetation roots. Therefore, the water supply for evapotranspiration $\left(\mathrm{ET}_{\mathrm{s}}\right)$ or soil transpiration was originated solely from unsaturated layer above the groundwater table. The reported results (Table 2) showed that the measured $\mathrm{ET}_{\mathrm{s}}$ or transpiration rates for each of four vegetation types were not consistent among different researches. However, under all of the four vegetation types, the transpiration rates measured using steady porometer and photosynthetic system were expectedly less than the $\mathrm{ET}_{\mathrm{g}}$ rates measured using the White method and the larger $\mathrm{ET}_{\mathrm{g}}$ was most likely resulted from the fact that the estimated $\mathrm{ET}_{\mathrm{g}}$ was composed of both evaporation and transpiration. It appears that those results obtained using different methods are not comparable because different assumptions were made and different measurement conditions were encountered (i.e., plant covers and meteorological conditions). However, these results are still somewhat valid in distinguishing evapotranspiration-dominated conditions from transpiration-dominated conditions within the unsaturated layers. This point can be further illustrated by this study. For example, the $\mathrm{ET}_{\mathrm{g}}$ at $\mathrm{AO}$ site (A. ordosica) can be regarded to have soly resulted from groundwater transpiration because the depth of groundwater table $(\sim 3.0 \mathrm{~m})$ was beyond the reach of evaporation. At AO site the estimated monthly $\mathrm{ET}_{\mathrm{s}}$ rate was $0.08 \mathrm{~mm} / \mathrm{d}$ for September and the monthly rate was $1.29 \mathrm{~mm} / \mathrm{d}$ for the rest of monitoring period (June, July, and August), being much less than the $\mathrm{ET}_{\mathrm{g}}$ estimated in this study (Table 2). Similar patterns were also observed at other sites (CE site, PA site, and SP site). 


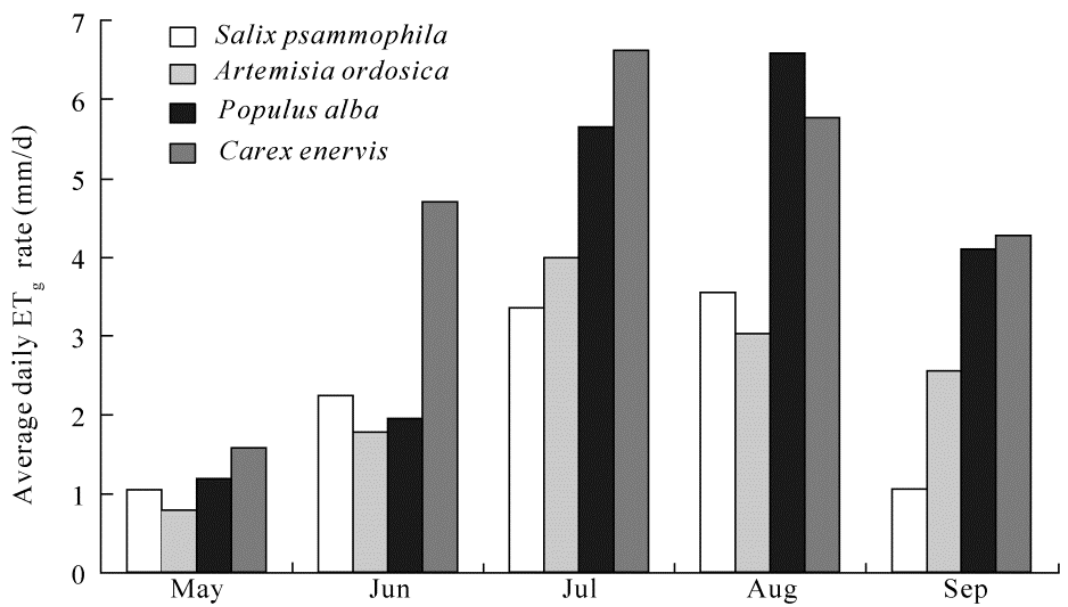

Fig. 7 Average daily $\mathrm{ET}_{\mathrm{g}}$ rates in each month at $\mathrm{CE}$ site, $\mathrm{PA}$ site, $\mathrm{AO}$ site and $\mathrm{SP}$ site, respectively

Table 2 Comparison of the measured or estimated ET rates or transpiration rates of S. psammophila, A. ordosica, $P$. alba and $C$. enervis using different methods

\begin{tabular}{|c|c|c|c|c|c|c|}
\hline \multirow{2}{*}{ Species } & \multicolumn{4}{|c|}{$\mathrm{ET}_{\mathrm{g}}, \mathrm{ET}_{\mathrm{s}}$ or transpiration rates $(\mathrm{mm} / \mathrm{d})$} & \multirow{2}{*}{ Measurement methods } & \multirow{2}{*}{ Data sources } \\
\hline & Jun & Jul & Aug & Sep & & \\
\hline \multirow[t]{4}{*}{ C. enervis } & - & 0.20 & 0.22 & - & Steady porometer, transpiration & Xu et al. (2008) \\
\hline & - & 0.17 & - & - & Steady porometer, transpiration & Yang et al. (2005) \\
\hline & 3.08 & - & - & - & Quick weighing, transpiration & Zhang et al. (2004) \\
\hline & 4.70 & 6.62 & 5.77 & 4.27 & White method, $\mathrm{ET}_{\mathrm{g}}$ & This study \\
\hline \multirow[t]{2}{*}{ P. alba } & - & - & 2.18 & - & Steady porometer, transpiration & Fang et al. (2006) \\
\hline & 1.95 & 5.65 & 6.59 & 4.10 & White method, $\mathrm{ET}_{\mathrm{g}}$ & This study \\
\hline \multirow[t]{3}{*}{ A. ordosica } & - & - & - & 0.08 & $\begin{array}{l}\text { Portable photosynthesis system, } \\
\text { transpiration }\end{array}$ & Zhang et al. (2007) \\
\hline & 0.89 & 1.50 & 1.49 & - & Water balance, $\mathrm{ET}_{\mathrm{s}}$ & Zhang et al. (2005) \\
\hline & 1.78 & 3.99 & 3.03 & 2.56 & White method, $\mathrm{ET}_{\mathrm{g}}$ & This study \\
\hline \multirow[t]{3}{*}{ S. psammophila } & - & - & - & 0.01 & $\begin{array}{l}\text { Portable photosynthesis system, } \\
\text { transpiration }\end{array}$ & Zhang et al. (2007) \\
\hline & 0.85 & 1.67 & 1.63 & - & Water balance, $\mathrm{ET}_{\mathrm{s}}$ & Zhang et al. (2005) \\
\hline & 2.24 & 3.36 & 3.55 & 1.06 & White method, $\mathrm{ET}_{\mathrm{g}}$ & This study \\
\hline
\end{tabular}

\section{Conclusions}

Estimating $\mathrm{ET}_{\mathrm{g}}$ using the diurnal water table fluctuations was an acceptable technique to obtain the $\mathrm{ET}_{\mathrm{g}}$ rates for psammophilous vegetation in desert areas with shallow groundwater. At site scales with four psammophilous vegetation types, $\mathrm{ET}_{\mathrm{g}}$ rates were not only sensitive to the variation of vegetation types and their growth stages, but also to the variation of daily meteorological conditions. We, the authors of this paper, suggest that the depth of groundwater table and the duration of drainage should be taken into account when the White method is applied to estimate the $S_{y}$ in shallow groundwater conditions. It should be stressed that the depth of groundwater table also has different effects on $\mathrm{ET}_{\mathrm{g}}$ for different vegetation types. Comparably speaking, the evapotranspiration (or the transpiration) for the vegetation solely relying on the water supply from unsaturated layers above the groundwater table as much less than that for the vegetation heavily relying on the water supply from shallow aquifers.

\section{Acknowledgements}

The research was funded by the National Natural Science Foundation of China $(41072184,41472220)$ and the 
Special Fund for Basic Scientific Research of Central Colleges, Chang'an University (310829162015). The authors thank WANG Yuhong, REN Lu, YU Xin and CHENG Yijie for performing partial field work.

\section{References}

Brooks R H, Corey A T. 1964. Hydraulic Properties of Porous Media. Hydrology Paper No.3. Fort Collins Colorado: Colorado State University.

Butler J J Jr, Kluitenberg G J, Whittemore D O, et al. 2007. A field investigation of phreatophyte-induced fluctuations in the water table. Water Resources Research, 43(2): W02404, doi: 10.1029/2005WR004627.

Cheng D H, Wang W K, Chen X H, et al. 2011. A model for evaluating the influence of water and salt on vegetation in a semi-arid desert region, northern China. Environmental Earth Sciences, 64(2): 337-346.

Cheng D H, Li Y, Chen X H, et al. 2013. Estimation of groundwater evapotranspiration using diurnal water table fluctuations in the Mu Us Desert, northern China. Journal of Hydrology, 490: 106-113.

Cooper D J, Sanderson J S, Stannard D I, et al. 2006. Effects of long-term water table drawdown on evapotranspiration and vegetation in an arid region phreatophyte community. Journal of Hydrology, 325(1-4): 21-34.

Duke H R. 1972. Capillary properties of soils-influence upon specific yield. Transactions of the ASAE, 15(4): 688-691.

Fang Y, Mu Z Z, Wang Y H, et al. 2006. Transpiration characteristics and its influencing factors of sixteen polar clones. Journal of Shandong University, 41(6): 168-172. (in Chinese)

Feng Q, Peng J Z, Li J G, et al. 2012. Using the concept of ecological groundwater level to evaluate shallow groundwater resources in hyperarid desert regions. Journal of Arid Land, 4(4): 378-389.

Freeze R, Cherry J. 1979. Groundwater. Englewood Cliffs, NJ: Prentice-Hall.

Gatewood J S, Robinson T W, Colby B R, et al. 1950. Use of Water by Bottom-Land Vegetation in Lower Safford Valley Arizona. US Geological Survey Water Supply Paper 1103. Washington, DC: US Government Printing Office.

Gerla P J. 1992. The relationship of water-table changes to the capillary fringe, evapotranspiration, and precipitation in intermittent wetlands. Wetlands, 12(2): 91-98.

Loheide S P II, Butler J J, Gorelick S M. 2005. Estimation of groundwater consumption by phreatophytes using diurnal water table fluctuations: a saturated-unsaturated flow assessment. Water Resources Research, 41(7): W07030.

Nachabe M H. 2002. Analytical expressions for transient specific yield and shallow water table drainage. Water Resources Research, 38(10): 11-1-11-7.

Rosenberry D O, Winter T C. 1997. Dynamics of water-table fluctuations in an upland between two prairie-pothole wetlands in North Dakota. Journal of Hydrology, 191(1-4): 266-289.

Tromble J M. 1997. Water requirements for mesquite (Prosopis juliflora). Journal of Hydrology, 34(1-2): 171-179.

Troxell H C. 1936. The diurnal fluctuation in the ground-water and flow of the Santa Ana river and its meaning. Eos, Transactions American Geophysical Union, 17(2): 496-504.

White W N. 1932. A method of estimating ground-water supplies based on discharge by plants and evaporation from soil: results of investigations in Escalante valley, Utah. In: US Geological Survey, Water-Supply Paper 659-A, U.S. Department of the Interior, Geological Survey.

Xu H F, Jin Y M, Liu X T, et al. 2008. The diurnal variation of transpiration and its relation to environmental factors for Carex meyeriana with varied pH. Journal of Irrigation and Drainage, 27(3): 112-115. (in Chinese)

Yan F, Wu B, Wang Y J. 2013. Estimating aboveground biomass in Mu Us Sandy Land using Landsat spectral derived vegetation indices over the past 30 years. Journal of Arid Land, 5(4): 521-530.

Yang Y Q, Xu H F, Jin Y M, et al. 2005. Diurnal variation of transpiration rate of Carex meyeriana and its relationship with environmental factors under different water conditions. Journal of Northeast Forestry University, 33(6): 52-54. (in Chinese)

Zhang C X, Zhang Q L, Chang J B. 2007. Diurnal variations of moisture physiology characteristic of a few plants in Hobq Desert. Journal of Nanjing Forestry University (Natural Sciences Edition), 31(4): 81-84. (in Chinese)

Zhang W J, Sun B P, Zhao T N, et al. 2004. A preliminary study on the transpiration rate hydrograph of Aneurolepidium dasystachys (Trin.) in its procreate period in the southern border of Mu Us Sandy Land. Research of Soil and Water Conservation, 11(3): 37-40. (in Chinese)

Zhang Z S, Li X R, Wang X P, et al. 2005. Evaporation and transpiration in re-vegetated desert area. Acta Ecologica Sinica, 25(10): 2484-2490. (in Chinese) 